\title{
CFD analysis of air flow through the LNG ambient air vaporizer with longitudinal finned tubes
}

\author{
Filip Lisowski ${ }^{1 *}$ and Edward Lisowski ${ }^{2}$ \\ ${ }^{1}$ Cracow University of Technology, Department of Machine Design and Composite Structures, Cracow, Poland \\ ${ }^{2}$ Cracow University of Technology, Department Applied Informatics, Cracow, Poland
}

\begin{abstract}
Ambient air vaporizers, depending on their efficiency, can be up to several meters high. Therefore, they can have a large outside surface area exposed to the wind. Forced air flow through the vaporizer structure have a beneficial effect on improving heat transfer from the environment. On the other hand, if the vaporizer is placed in the region of significant wind velocities, the wind forces acting on the structure can be considerable. This paper presents CFD analysis of air flow through the structure of the ambient air vaporizer with a $6 \times 6$ finned tube array. The effect of changing wind direction on the wind pressure and wind velocity distributions is investigated.
\end{abstract}

\section{Introduction}

Natural gas can be delivered by sea and by land using pipelines or tanks. Because the cost of maintaining the pipelines increase with length, it is not the most efficient way to deliver gas over long distances. Currently, the primary one for long-distance delivery is LNG technology, for which the volume of gas is reduced about 600 times after liquefaction. The LNG supply chain consists of four main stages such as exploration, extraction, liquefaction, transportation, regasification and distribution. [1]. In the liquefaction process, natural gas is cooled to about $160^{\circ} \mathrm{C}$ below zero and a liquid state is obtained. This results in a significant volume reduction. Large gas carriers are used in long-distance offshore transport in order to deliver LNG to marine terminals. In turn, liquefied natural gas is typically delivered to end users overland in insulated LNG cryogenic tanks [2-3]. LNG regasification is required before the final use of natural gas. This stage is crucial for energy conversion efficiency. Moreover, it can be strongly influenced by geographic and meteorological conditions, which in turn are important in the choice of technology [4-6]. Regasification process requires energy input in the form of heat. The most common energy sources for heat exchange technologies in use include ambient air, seawater, cooling tower water, steam, electricity, or combustion of the gas itself. The use of ambient air as a source of energy is of great interest due to its unlimited capacity, zero environmental impact and lack of operational complexity of the equipment [7]. The typical structure of LNG ambient air vaporizers, which are most often used in regasification stations, contains an array of longitudinal aluminium finned tubes arranged vertically.

\section{The object of study}

Extruded aluminium profiles with longitudinal lamellas are generally used in the construction of LNG ambient air vaporizers. Longitudinal finned tubes for typical ambient air vaporizer applications typically have from 2 to 16 fins. In this study, a vaporizer with a $6 \times 6$ tube array as shown in Fig.1 was analysed. A single finned tube contained 16 fins evenly distributed around the perimeter of the central pipe, the outer diameter of which was $30 \mathrm{~mm}$. The cross section of the single finned tube was inscribed in a square with dimensions of $175 \times 175 \mathrm{~mm}$. All the wall thicknesses were assumed equal to $2 \mathrm{~mm}$. The pitch of the profile arrangement was consistent at $350 \mathrm{~mm}$.

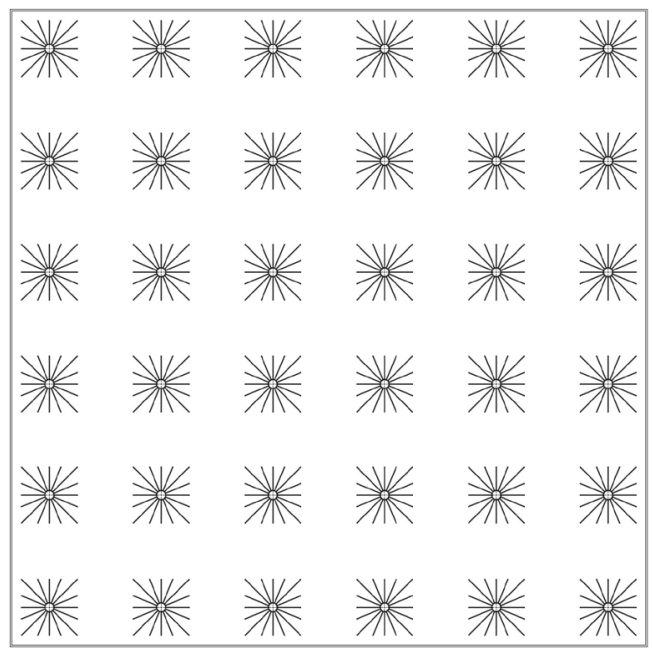

Fig. 1. 6x6 finned tube array of the ambient air vaporizer.

\footnotetext{
* Corresponding author: filip.lisowski@.pk.edu.pl
} 


\section{CFD analysis}

The analysis of the wind action on the ambient air vaporizer structure was performed using computational fluid dynamics software ANSYS/Fluent. During the air flow through the structure of the ambient air vaporizer, there are no conditions for laminar flow due to the geometry of the finned tubes, therefore a standard k- $\varepsilon$ turbulence model was adopted in the analysis.

\subsection{Mesh and analysis assumptions}

Discrete models were prepared for analyses with wind directions $\alpha$ of $90^{\circ}$ and $45^{\circ}$. The example of the mesh for the case of perpendicular wind direction and the detail of the mesh around the finned tube profile were shown in Figs. 2-3. For the problem under consideration, 2D models were adopted as the wind velocity component in front of the vaporizer has only one flow direction and two flow directions inside the vaporizer structure. The following assumptions were made for CFD analysis:

- All tubes were of the same cross-section.

- There were no other objects in front of and behind the vaporiser.

- There were no other objects on the sides of vaporizer at least at a distance of 1 meter.

- The air velocity was constant at a distance of $2 \mathrm{~m}$ in front of the vaporiser.

- Air density $\rho=1.225 \mathrm{~kg} / \mathrm{m}^{3}$,

- $\quad$ Air viscosity $\mu=1.7894 \mathrm{e}-05 \mathrm{~kg} / \mathrm{ms}$.

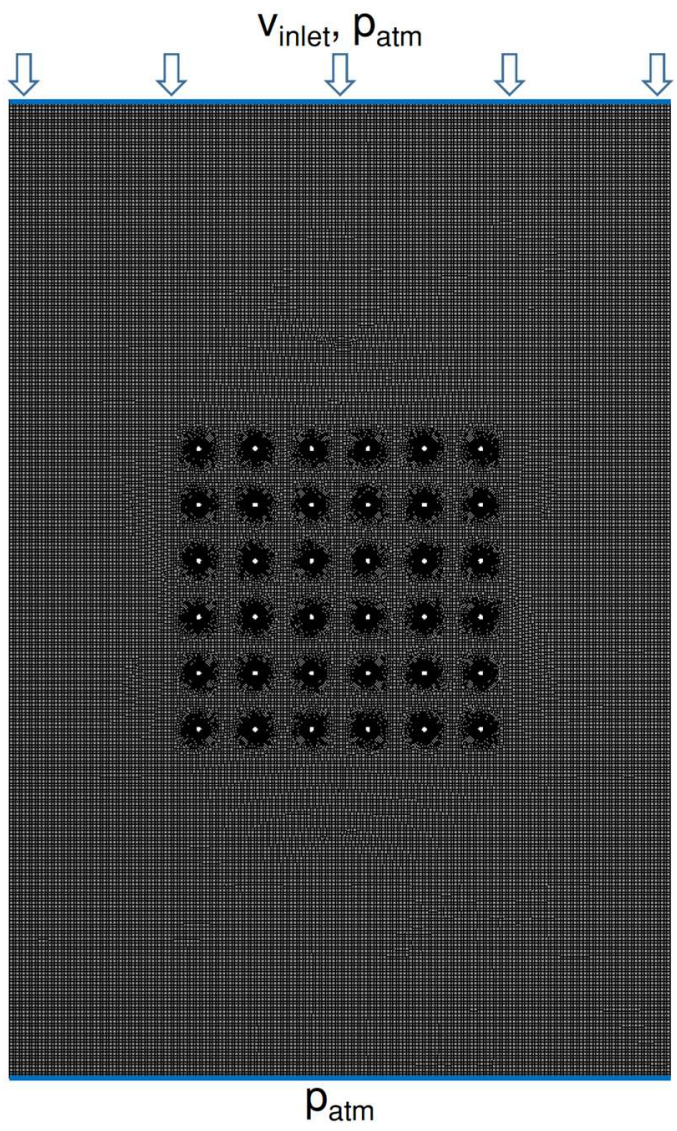

Fig. 2. Mesh for wind direction of $\alpha=90^{\circ}$.

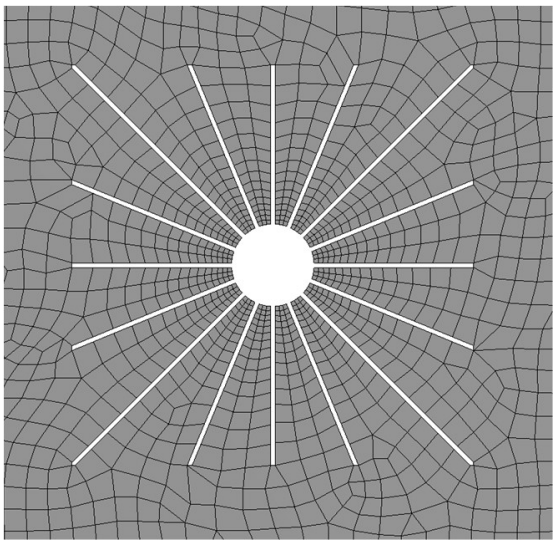

Fig. 3. Mesh detail around tube finned tube profile

\subsection{Results}

The results of the CFD analyses were related to one metre of longitudinal finned tubes length. The obtained distributions of wind pressure were presented in Figs. 45 whereas wind velocity distribution were shown in Figs. 6-7.

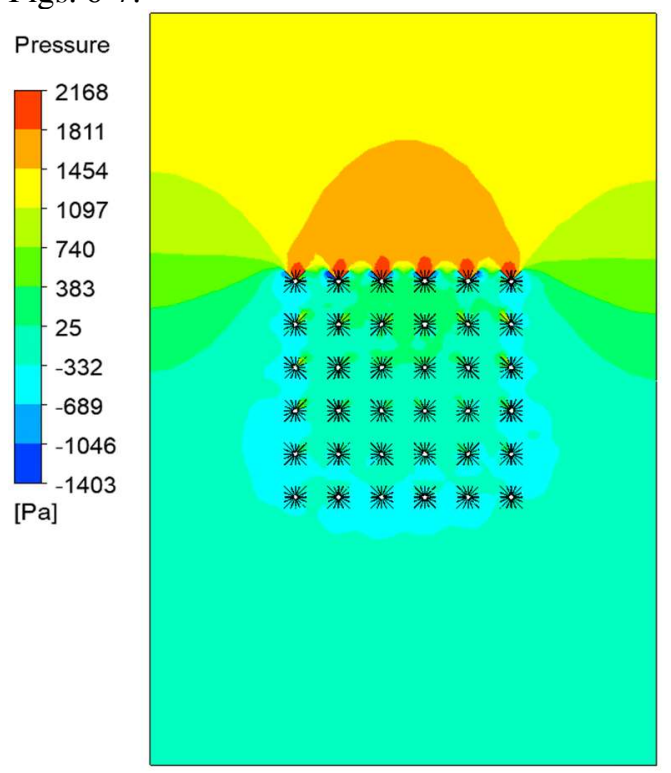

Fig. 4. Wind pressure distribution, $\alpha=90^{\circ}$.

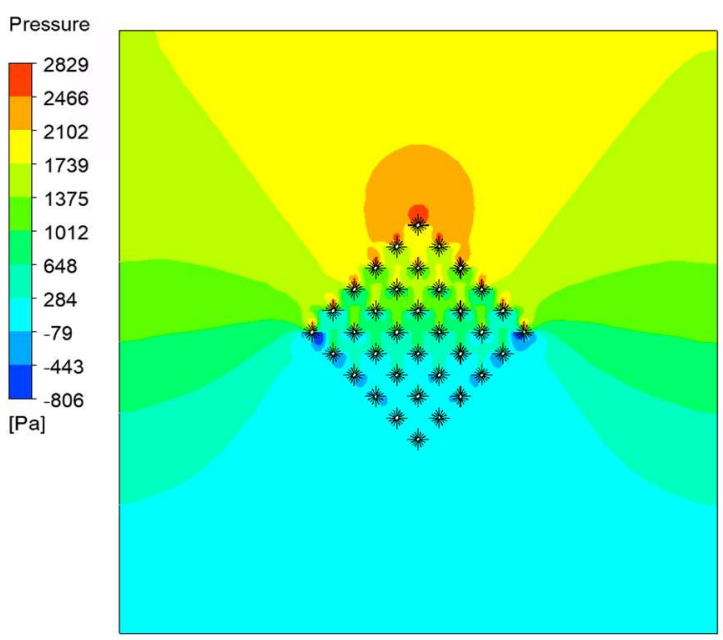

Fig. 5. Wind pressure distribution, $\alpha=45^{\circ}$. 


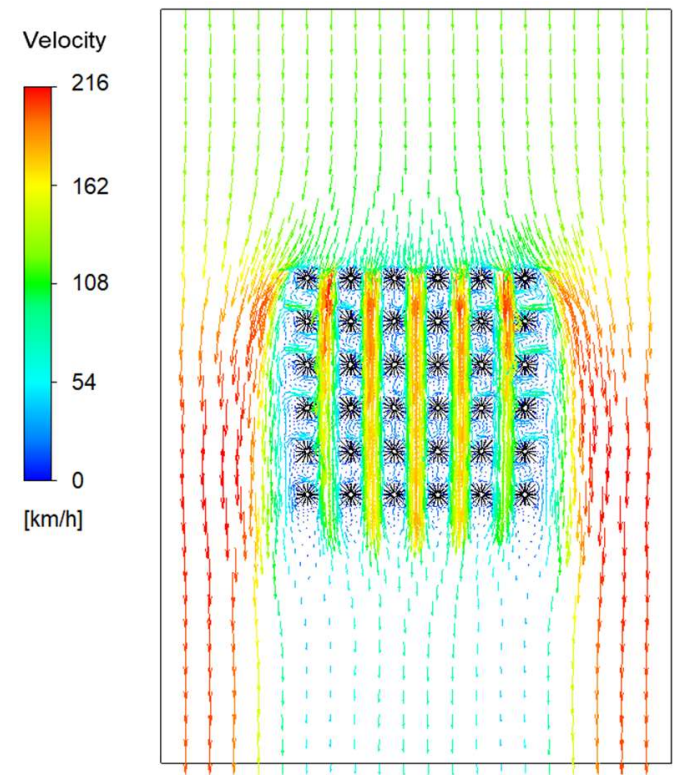

Fig. 6. Wind velocity distribution, $\alpha=90^{\circ}$.

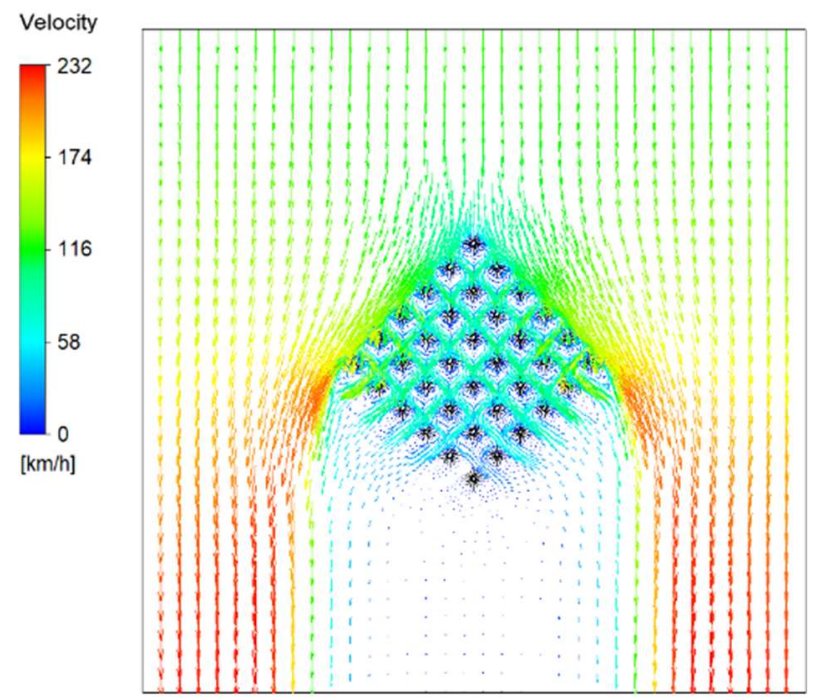

Fig. 7. Wind velocity distribution, $\alpha=45^{\circ}$.

\section{Conclusions}

Comparing the results of the analysis for constant wind velocity, it can be noticed that wind pressure distribution on the vaporizer structure and maximum load acting locally on the individual tubes significantly depended on the wind direction. When considering the perpendicular wind direction, the tubes in the first row were the most loaded. However, this load was more evenly distributed among the individual ones. In contrast, for wind direction $\alpha=45^{\circ}$, the maximum wind pressure on the most loaded tube was more than $20 \%$ higher. When comparing the wind velocities inside the vaporizer structure it can be observed that for perpendicular wind direction the wind velocities between the tubes were much higher.

\section{References}

1. R. Grønhaug, M. Christiansen, Supply Chain Optimization for the Liquefied Natural Gas Business. In: Nunen J, Speranza M, Bertazzi L. (eds) Innovations in Distribution Logistics. Lecture Notes in Economics and Mathematical Systems 2009, 619, Springer, Berlin, Heidelberg, doi:10.1007/978-3-540-92944-4.

2. E. Lisowski, F. Lisowski, Study on thermal insulation of liquefied natural gas cryogenic road tanker, Therm. Sci. 23, 4 (2019), S1381-S1391, DOI: 10.2298/TSCI19S4381L.

3. F. Lisowski, E. Lisowski, Design of internal supports for double-walled liquefied natural gas road tanker, Heat Transfer Eng. (2021), 1-10, DOI: $10.1080 / 01457632.2021 .1874653$

4. R. Agarwal, T.J. Rainey, S.M.A Rahman et. al. LNG Regasification Terminals: The Role of Geography and Meteorology on Technology Choices, Energies. 10, 2152 (2017), DOI:10.3390/en10122152.

5. X. Tiana, W. Jiaoa, L. Rena, S. Liub, T. Liua, Research on climate zoning indicators for operating environment of liquefied natural gas ambient air vaporizer, Sustainable Cities and Society 60, 102186 (2020), DOI:10.1016/j.scs.2020.102186.

6. H.M. Jeong, H.S. Chung, E. Djajadiwinata et al. Experimental study on the characteristics of longitudinal fin air-heating vaporizers in different seasons. J. Mech. Sci. Technol. 22 (2008), 981990, DOI:10.1007/s12206-007-1216-1.

7. Cryogenic Industries. The Advantages of Using Ambient Air Vaporizers Throughout the Entire LNG Market, Frostbyte, A newsletter from Cryogenic Industries, Winter 2015, Available online: https://www.nikkisoceig.com/frostbyte/wpcontent/uploads/2015/03/2015_Winter_FrostByte_ low_res_FINAL1.pdf 